\title{
Monolithic silsesquioxane materials with well-defined pore structure - ERRATUM
}

\author{
Kazuyoshi Kanamori
}

doi: 10.1557/jmr.2014.332, Published by Materials Research Society with Cambridge University Press, 25 November 2014.

In Kanamori $^{1}$, the following reference should be deleted:

101. A. Shimojima and K. Kuroda: Designed synthesis of nanostructured siloxane-organic hybrids from amphiphilic silicon-based precursors. Chem. Rec. 6, 53-63 (2006).

Consequently, references should be renumbered as:

101. K. Kuroda, A. Shimojima, K. Kawahara, R. Wakabayashi, Y. Tamura, Y. Asakura, and M. Kitahara: Utilization of alkoxysilyl groups for the creation of structurally controlled siloxane-based nanomaterials. Chem. Mater. 26, 211-220 (2014).

102. J.N. Hay, D. Porter, and H.M. Raval: A versatile route to organically-modified silicas and porous silicas via the non-hydrolytic sol-gel process. J. Mater. Chem. 10, 1811-1818 (2000).

103. P.H. Mutin and A. Vioux: Nonhydrolytic processing of oxide-based materials: Simple routes to control homogeneity, morphology, and nanostructure. Chem. Mater. 21, 582-596 (2009).

104. Y. Liu, M. Wang, Z. Li, H. Liu, P. He, and J. Li: Preparation of porous aminopropylsilsesquioxane by a nonhydrolytic sol-gel method in ionic liquid solvent. Langmuir 21, 1618-1622 (2005).

105. A. Arkhireeva, J.N. Hay, and M. Manzano: Preparation of silsesquioxane particles via a nonhydrolytic sol-gel route. Chem. Mater. 17, 875-880 (2005).

106. A. González-Campo, E.J. Juárez-Pérez, C. Viñas, B. Boury, R. Sillanpää, R. Kivekäs, and R. Núñez: Carboranyl substituted siloxanes and octasilsesquioxanes: Synthesis, characterization, and reactivity. Macromolecules 41, 8458-8466 (2008).

107. D.J. Boday, S. Tolbert, M.W. Keller, Z. Li, J.T. Wertz, B. Muriithi, and D.A. Loy: Non-hydrolytic formation of silica and polysilsesquioxane particles from alkoxysilane monomers with formic acid in toluene/tetrahydrofuran solutions. J. Nanopart. Res. 16, 2313 (2014).

The publisher regrets the mistake.

\section{REFERENCE}

1. K. Kanamori: Monolithic silsesquioxane materials with well-defined pore structure. J. Mater. Res. 29(23), 2773-2786 (2014). 